\title{
ANORGASMIA - O SILÊNCIO DO PRAZER
}

\author{
Ana Regina de Oliveira Moura ${ }^{2}$
}

\section{ANORGASMIA. THE SILENCE OF PLEASURE}

Resumo: O objetivo deste artigo é chamar atenção para esse tema polêmico e ainda tão presente em nossa sociedade bem como esclarecer suas características, definições, causas e possíveis soluções.

Palavras-chave: Sexualidade; orgasmo; prazer; disfunção sexual

Abstract: The aim in this article is to call the attention to this polemic subject, very present in our societ, and also to expose its characteristics, and different causes and its possible solutions.

Keywords: Sexuality; orgasm; pleasure; sexual disfunction.

\section{Introdução}

Em tempos bem remotos a mulher considerada um objeto, não tinha direito a amar, escolher, nem poder de decisão. Não podia exercer sua sexualidade e nem sequer falar em atingir clímax, orgasmo. Esse direito só cabia às mulheres de vida fácil, às prostitutas.

Na década de 60, com o advento da pílula, a história tomou um novo rumo, ocasionando uma transformação radical no que diz respeito à sexualidade feminina. O sexo foi dissociado da procriação e ligado ao prazer. A partir daí houve uma crescente propagação do mesmo, levando as mulheres a reivindicarem e conseqüentemente, conquistarem o direito a esse prazer.

Bióloga, Pós-Graduada em Educação Sexual pela UGF/RJ, Especialista em Sexualidade Humana pela SBRASH, Coordenadora do Programa de Orientação Afetivo-Sexual da Secretaria Municipal de Educação em Maceió/AL. e-mail: anareginaom@hotmail.com 
Atualmente, após dois milênios de silêncio, apesar de reivindicações contextualizadas, observa-se a neurose das mulheres de atingirem orgasmos múltiplos ou mesmo simples, uma vez que tornou-se exigência fundamental da sociedade para que as mesmas não fossem rotuladas de frígidas ou anorgásmicas.

\section{Anorgasmia}

Durante séculos a posição da mulher na sociedade era de submissão ao homem e de plena e exclusiva dedicação aos seus caprichos. Devido ao avanço da tecnologia, de estudos voltados à área da sexologia e da busca pela sua liberdade, a mulher começou a desfrutar dos prazeres da sexualidade, até então destinada apenas ao universo masculino.

No final do século XIX alguns estudiosos como Freud, Havelock Hellis, M. Hirschfeld e Van de Velde apresentaram uma série de comportamentos e atitudes que interferiram de forma significativa no campo da sexualidade, com registros da época, como se pode observar:

[...] a possibilidade de orgasmos múltiplos nas mulheres quando bem estimuladas, a interferência do tempo da relação sexual nas possibilidades de prazer, o fato de que a repressão sexual nas mulheres era um dos fatores que as levava à 'frigidez' e que um outro fator estava vinculado à falta de conhecimento masculino quanto à importância do clitóris para a excitação da mulher, além de já sistematizarem o ciclo da atividade sexual em fases. (ANDRADE-SILVA, JURBERG, SERAPIÃO, JURBERG, 2002, p. 97-98)

Apesar do despertar dessas revelações não houve uma ampla aceitação e divulgação como no caso dos manuais de patologias e perversões que dominaram o início do século XX, visto que o conhecimento das ciências sexuais estava voltado para questões médico higienistas, ressaltando problemas de doenças, pecados, desvios, onde tinha a reprodução como finalidade básica da sexualidade.

Alfred Kinsey e seus colaboradores, a partir da metade do século XX, contribuíram de forma significativa, quando estudando o comportamento sexual humano descreveram práticas sexuais consideradas como pervertidas em indivíduos não patológicos; assim como Masters e Johnson ao publicarem seu livro "Human Sexual Response" em 1966 quando retrataram a importância do ciclo da resposta sexual humana. Estas publicações serviram como referências mundiais não só na época como nos dias atuais, por responderem de forma objetiva a questionamentos afins. 
O comportamento sexual humano é bastante diverso e é determinado por um conjunto de fatores como os relacionamentos dos indivíduos, as circunstâncias da vida e a cultura em que se vive. De um modo geral, esses indivíduos buscam cada vez mais informações, procuram se conhecer melhor para a apreciação de uma vida sexual mais saudável e feliz. Isto dificulta uma definição precisa do que é "normal" em termos de sexualidade, todavia, possibilita afirmar que em relação aos padrões normais sexuais, deverá haver um entendimento mútuo entre os pares no exercício desta e o respeito aos limites um do outro assim como o espaço da sociedade em que se vive.

Segundo Vitiello $(1997,142)$, “[... ] se imaginarmos a resposta sexual humana e seus três grupos de condicionantes importantes (componentes orgânico, social e psicológico), poderemos melhor entender seus pressupostos normais". Do ponto de vista orgânico, quando a resposta sexual restringe-se à função biológica de forma satisfatória pode-se falar em função sexual; porém quando ela não desempenha seu papel adequadamente pode-se chamar de disfunção sexual. Esta pode ocorrer no mecanismo da ereção peniana sendo denominada de impotência ou disfunção erétil; ou no mecanismo de desencadeamento do orgasmo feminino no que será chamado frigidez - nome criado por Freud no início do século XX para descrever a mulher "fria" ou "frígida", aquela que não consegue atingir o desejo sexual e que atualmente é conhecida como anorgásmica.

Sendo a anorgasmia a inibição do orgasmo feminino que se manifesta após a excitação sexual, ela pode estar relacionada a questões psicológicas e biológicas como a falta de intimidade com o próprio corpo e com o parceiro, fatores religiosos, mitos e tabus, falta de informação, insegurança, medo de engravidar, traumas sexuais e baixa auto-estima.

Entre os fatores orgânicos podemos destacar problemas com a tireóide, circulação sanguínea, cardiopatias, obesidade, diabetes, o uso abusivo de álcool, cigarro e demais drogas. Estas situações podem comprometer a excitação e, em conseqüência, a chegada ao orgasmo.

Tendo como foco principal à disfunção sexual, o tratamento consiste em pesquisar a causa primária analisando qual o aspecto a este ligado. Se a questão for clínica o melhor caminho é procurar um médico para uma avaliação. Se existir alguma dificuldade emocional ou psicológica, recomenda-se a 
psicoterapia podendo estar embasada na terapia individual, na de casal ou nas duas associadas. Contanto que deve ser acompanhado por um profissional que possua conhecimentos dos mecanismos da resposta sexual, assim como os seus estágios.

Apesar das mulheres não mais associarem a sexualidade ou mesmo o sexo a fatores ligados exclusivamente à reprodução, e desejarem sentir prazer em seus relacionamentos sexuais, elas têm dificuldades em atingir o clímax. Segundo pesquisa realizada em 2003 pelo Prosex ${ }^{2}$, cerca de 30\% das mulheres brasileiras têm este problema.

Para a psiquiatra e coordenadora do Prosex Carmita Abdo (PEROZIN, L., 2004), os problemas da vida moderna como a depressão, a ansiedade e o estresse são fatores inibidores pela busca do prazer. Além desses fatores, outros, como inabilidade, inexperiência, desinteresse, falta de tempo ou de local adequado e mesmo o desconhecimento do próprio corpo, também são responsáveis pela chamada anorgasmia.

Existem mulheres que apesar de anos de convivência a dois, mantendo relaçōes sexuais ditas "normais" não conhecem o "prazer do orgasmo", estas sofrem de anorgasmia primária; se elas tinham orgasmos e deixaram de tê-los de forma sistemática, têm anorgasmia secundária; se mesmo sendo estimuladas nunca o atingiram nem por intermédio do coito nem por intermédio da masturbação, sofrem de anorgasmia total e quando elas para atingirem o orgasmo, necessitam de circunstâncias específicas, possuem anorgasmia situacional.

Não muito incomum a dificuldade em atingir o orgasmo pode ocorrer mesmo que haja interesse e que as outras respostas sejam satisfatórias para a realização do ato. Assim, a mulher pode experimentar todas as fases que antecedem o orgasmo; passando pela fase do desejo; da excitação - quando aproveita as carícias de seu parceiro, porém algo a bloqueia no momento do clímax fazendo-a silenciar. Um silêncio que pode ser por negação, por medo, por fingimento, por culpa, pois ela ainda está presa a valores morais, religiosos, éticos, estéticos, sem conseguir se libertar de uma educação sexual castradora e dessa sociedade repressora que invade e priva a obtenção de um prazer que pode ser desvendado, revelado e saboreado da melhor forma possível.

2 Projeto de Sexualidade do Hospital das Clínicas de São Paulo (In: PEROZIN, L. Frigidez ou anorgasmia. Vida e Saúde. Disponível em: <http:||saude.terra.com.br/inteira/0..0l1296219El1517.00.html >. Acesso em 10.06.07. 


\section{Referências bibliográficas}

ANDRADE-SILVA, M.C.; JURBERG, M.B.; SERAPIÃO, J.J.; JURBERG, P. Sexologia - Interdisciplinaridade nos modelos clínicos, educacionais e na pesquisa, 2 ed. rev. e amp. Rio de Janeiro: Universidade Gama Filho, 2002. 279 p.

ANDRADE-SILVA, M.C.; SERAPIÃO, J. J.; JURBERG, P. Sexologia Fundamentos para uma visão interdisciplinar. Rio de Janeiro: Universidade Gama Filho, 1977. 248 p.

CARIDADE, A. Psicossomática do prazer feminino. Revista Brasileira de Sexualidade Humana, v. 10, n. 1. p. 65-69. São Paulo: Iglu. 1999. LINS, R. N.; BRAGA, F. Ausência de orgasmo. O Livro de Ouro do Sexo, p. 237-245. Rio de Janeiro: Ediouro. 2005.

PEROZIN, L. Frigidez ou anorgasmia. Vida e Saúde. Disponível em: <http:IIsaude.terra.com.br/inteira/O..OI1296219-EI1517.00.html>. Acesso em 10.06.07.

PEROZIN, L. Anorgasmia: quando elas “falham”. Netmarkt. Disponível em: <http:Innetmarkt.com.br/noticia2004/1787.html>. Acesos em 12.06.07.

VITIELLO, N. Anatomia e fisiologia da sexualidade. A resposta sexual humana.

In: VITIELLO, N.; RODRIGUES JR, O. M. As Bases Anatômicas e Funcionais do exercício da sexualidade. São Paulo: Iglu. 1997.p. 141-153. 